\title{
Dual antitumour effect of 5 -azacytidine by inducing a breakdown of resistance-mediating factors and epigenetic modulation
}

\author{
Sascha Venturelli, ${ }^{1}$ Alexander Berger, ${ }^{1}$ Timo Weiland, ${ }^{1}$ Martina Zimmermann, ${ }^{1}$ \\ Sabine Häcker, ${ }^{2}$ Christoph Peter, ${ }^{1}$ Sebastian Wesselborg, ${ }^{1}$ Alfred Königsrainer, ${ }^{3}$ \\ Thomas S Weiss, ${ }^{4}$ Michael Gregor, ${ }^{1}$ Simone Fulda, ${ }^{2}$ Ulrich M Lauer, ${ }^{1}$ Michael Bitzer ${ }^{1}$
}

\begin{abstract}
- Additional figures and Materials and methods are published online only. To view these files please visit the journal online (http://gut.bmj. com).

${ }^{1}$ Department of Internal Medicine I, Medical University Hospital, Tuebingen, Germany 'University Children's Hospital, Ulm University, Ulm, Germany ${ }^{3}$ Department of General, Visceral and Transplant Surgery, University Hospital, Tuebingen, Germany

${ }^{4}$ Center for Liver Cell Research, University Hospital, Regensburg, Germany
\end{abstract}

\section{Correspondence to}

Michael Bitzer, Department of Internal Medicine I, Medical University Hospital, Otfried-Mueller-Str. 10 D-72076 Tuebingen, Germany; michael.bitzer@uni-tuebingen. de

Revised 10 August 2010 Accepted 13 September 2010 Published Online First 23 November 2010

\section{ABSTRACT}

Background The cytokine tumour necrosis factor-related apoptosis-inducing ligand (TRAIL) has shown promising anticancer activity in early clinical settings by selectively inducing apoptosis in different tumour types. However, some tumour entities such as hepatocellular carcinoma (HCC) display an inherent resistance to TRAIL. A huge effort has been made to unravel strategies for a clinically applicable sensitisation of resistant cancer cells to TRAIL. Reversible epigenetic alterations such as DNA methylation play a major role in development, maintenance and resistance phenomena of tumour cells. Currently, several clinical trials are exploiting the potential of epigenetic drugs, such as 5-azacytidine (5-aza-CR) or 5-aza-2' -deoxycytidine (5-aza-dC) to break primary or secondary resistance phenomena of cancer cells. Therefore, 5-aza-CR and 5-aza-dC were investigated in the context of TRAIL resistance. Methods Alterations in proliferation, apoptosis regulatory proteins and toxicity were investigated in TRAIL-resistant hepatoma, and also in renal, colon and pancreatic cancer cells as well as non-transformed human-derived primary hepatocytes, tissue slices isolated from human liver and non-malignant colon cells, all of which had been exposed to demethylating drugs and/or TRAIL.

Results Within hours, 5-aza-CR but not 5-aza-dC sensitised in vitro cultured tumour cells to TRAIL, first by activating caspases, followed by a subsequent induction of apoptosis. This surprisingly rapid sensitisation was confirmed in vivo employing a chorioallantoic membrane assay. As a major mechanism, a 5-aza-CR-induced inhibition of cellular protein synthesis was found which led to a breakdown of tumour-protecting factors such as the antiapoptotic factor FLICE inhibitory protein (FLIP). Importantly, TRAIL and 5-aza-CR did not induce relevant toxicity or apoptosis in primary hepatocytes, liver slices from different human donors and in normal colon cells. Conclusions Molecular evidence is provided for a novel 5-aza-CR-based translational approach enabling a twofold treatment of apoptosis-resistant tumour entities, not only by an epigenetic reversion of the malignancy-associated phenotype but also by an efficient resensitisation to apoptosis-inducing substances such as TRAIL.

\section{INTRODUCTION}

For decades no substantial progress could be achieved in the treatment of advanced hepatocellular carcinoma (HCC). Resistance phenomena

\section{Significance of this study}

What is already known about this subject?

- Epigenetic alterations play a major role in the development and maintenance of hepatocellular carcinoma (HCC) and other tumour entities with a hypermethylation of $\mathrm{CpG}$ islands specifically within promotor regions of cellular control genes, inducing their functional shut-down.

- Epigenetic alterations constitute a highly interesting therapeutic target because of their potential reversibility.

- The two most advanced epigenetic drugs to reverse aberrant methylation events in cancer cells are 5-azacytidine (5-aza-CR, Vidaza) and 5-aza-2' -deoxycytidine (5-aza-dC, Decitabine, Dacogen). These are today the only DNA methyltransferase inhibitors with FDA approval and are used for the treatment of myelodysplastic syndrome and acute myeloid leukaemia.

- The current interest in the proapoptotic signalling of TRAIL in cancer cells is reflected by the fact that at least six different TRAIL receptor-targeted therapeutics (antibodies/recombinant proteins) have already been tested in clinical trials.

- Apoptosis-resistant cancer cells comprise a major problem in clinical oncology requiring clinically applicable drugs, which efficiently interfere with apoptosis-protecting factors (very recently reviewed by Schulze-Bergkamen et al ${ }^{1}$ ).

prevented the development of new treatment strategies. Sorafenib, a multikinase inhibitor, was the first substance for which a modest survival benefit could be proven recently ${ }^{2}$; however, new therapeutic principles are urgently needed to improve further the perspective of patients with HCC. Two innovative approaches in this context are the modulation of epigenetic alterations in tumour cells and the application of tumour-selective cytokines such as the tumour necrosis factorrelated apoptosis-inducing ligand (TRAIL).

Epigenetic alterations play a major role in the development and maintenance of HCC and also other tumour entities with a hypermethylation of $\mathrm{CpG}$ islands specifically within promotor regions of cellular control genes, inducing their functional shut-down. ${ }^{3-5}$ These alterations constitute a highly interesting therapeutic target because of 


\section{Significance of this study}

\section{What are the new findings?}

- The demethylating drug 5-aza-CR leads to a rapid breakdown of tumour-protecting factors which sensitises resistant cancer cells for an application of apoptosis-inducing therapeutics such as the cytokine TRAIL.

- Surprisingly, we found out that the sensitisation to TRAIL is not mediated via a suspected epigenetic modulation of methylation events but rather by a 5 -aza-CR-inherent shutdown of cellular protein biosynthesis.

- Primary human hepatocytes, liver tissue slices isolated from different human donors and non-malignant colon cells did not show relevant signs of toxicity during a combination treatment with 5-aza-CR and TRAIL, implying a broad therapeutic window for this novel approach.

- Thus, 5-aza-CR but not the closely related compound 5-aza-dC harbours a dual antitumour activity in apoptosis/TRAlLresistant cancer cells by (1) inducing a breakdown of tumour-protecting factors, thereby enabling the execution of apoptosis, and (2) in the remaining cancer cells having an epigenetic targeted approach by a reversion of the malignancy-associated methylation phenotype.

\section{How might it impact on clinical practice in the foreseeable future?}

- Worldwide, a huge effort is being made to identify clinically applicable drugs which are able to downregulate apoptosis-protecting factors, these being a major hallmark in cancer cells.

- The basic concept of using a well-known drug to overcome resistance to treatment which harbours a considerable antitumour activity by a completely different mechanism on its own is quite attractive for translation into clinical trials in the near future.

- The discovery that the 5-aza-CR-inherent activity to block protein biosynthesis sensitises so far resistant cancer cells, such as HCC, renal, colon or pancreatic cancer, to TRAIL or even other apoptosis-mediated therapeutic strategies will strongly impact the design of future clinical trials that include epigenetic active compounds. In contrast to the closely related epigenetic drug 5-aza- $\mathrm{dC}$, the application of 5-aza-CR adds a further molecular mechanism in the fight against cancer. 5-Aza-CR opens up the possibility to use TRAIL or TRAIL-related compounds even in tumours harbouring a primary resistance.

their potential reversibility. Two demethylating drugs, 5-azacytidine (5-aza-CR) and 5-aza-2'-deoxycytidine (5-aza-dC), already have been approved by the Food and Drug Administration (FDA) for the treatment of myelodysplastic syndrome. ${ }^{6} 7$ More than 40 years ago, both compounds were developed as classical cytostatic agents, ${ }^{8}$ but later were found to work indirectly on tumour cell proliferation by inhibiting DNA methyltransferases (DNMTs) in vitro and in vivo. Interestingly, 5-aza-CR, but not 5-aza-dC, also inhibits cellular protein synthesis, caused by blocking rRNA formation and disaggregation of polyribosomes. ${ }^{9-11}$

The current interest in TRAIL signalling is reflected by the fact that at least six different TRAIL receptor-targeted therapeutics (antibodies/recombinant proteins) have already been tested in clinical trials. ${ }^{12}$ Specifically, a huge effort has been undertaken to discover substances that sensitise HCC cells which as inherently resistant to TRAIL, such as classical chemotherapeutics, ${ }^{13}$ adenoviral gene transfer, ${ }^{14}$ proteasome, c-Jun N-terminal kinase (JNK) or histone deacetylase inhibitors. ${ }^{15-17}$ Recently, approaches combining demethylating drugs together with TRAIL have been investigated. ${ }^{18-21}$ However, these studies mostly focused on 5 -aza-dC and did not specifically investigate 5-aza-CR's inherent mode of action as a cellular protein synthesis inhibitor.

In contrast, our work unravels new mechanisms and opens up new perspectives for the clinical application of 5-aza-CR by demonstrating that 5 -aza-CR mediates a sensitisation of hepatoma, renal, colon and pancreatic cancer cells to TRAIL in a p53independent fashion. As a possible mechanism, an inhibition of cellular protein synthesis is suggested, which was found also to comprise the translational inhibition of the antiapoptotic factor FLICE inhibitory protein (FLIP). Importantly, a detailed characterisation of this combinatorial approach on primary human hepatocytes, liver tissue slices and non-malignant colon cells did not show signs of toxicity. Finally, employing a chorioallantoic membrane (CAM) assay with hepatoma cells, we could also prove a profound antitumour acitivity in vivo. Therefore, 5-azaCR seems to constitute an ideal TRAIL sensitiser candidate for further clinical evaluation in the context not only of HCC treatment, but also of other TRAIL-resistant tumour entities.

\section{MATERIALS AND METHODS \\ Cell culture}

Human-derived tumour cell lines HepG2, Hep3B and A-498 were obtained from the German Collection of Microorganisms and Cell Cultures (DSMZ, Braunschweig, Germany) and cultured in Dulbecco's modified Eagle's medium (DMEM; Lonza Bioscience, Verviers, Belgium) with 10\% fetal calf serum (FCS) and $2 \mathrm{mmol} / \mathrm{l}$ L-glutamine (Life Technologies, Rockville, Maryland, USA). Primary human hepatocytes (PHHs) from different donors were provided by T.S. Weiss according to the guidelines and informed consent of the charitable state-controlled Human Tissue \& Cell Research Foundation HTCR (http://www.htcr.de) and cultured as described ${ }^{22}$; in brief, in DMEM with $100 \mathrm{U} / \mathrm{ml}$ penicillin and streptomycin (Serva, Heidelberg, Germany), $2 \mathrm{mmol} / \mathrm{l} \mathrm{L-gluta-}$ mine, $18.8 \mu \mathrm{g} / \mathrm{ml}$ hydrocortisone (Merck, Darmstadt, Germany) and $1.68 \mathrm{mU} / \mathrm{ml}$ insulin (Novo Nordisk, Bagsvaerd, Denmark).

\section{Reagents}

5-Aza-CR (Sigma-Aldrich, Taufkirchen, Germany), 5-aza-dC (Sigma-Aldrich), cycloheximide (CHX; Carl Roth, Karlsruhe, Germany), fluorescein diacetate (Sigma-Aldrich), staurosporine (STS; Biomol, Hamburg, Germany), sulforhodamine B (SRB; Sigma-Aldrich), soluble recombinant human TRAIL (residues 114-281; Calbiochem, Schwalbach, Germany).

\section{Fluorescence-activated cell sorting (FACS) analysis}

HepG2 $\left(7.5 \times 10^{4}\right.$ cells/well $)$ were seeded in 24 -well plates. After incubation cells were washed once in phosphate-buffered saline (PBS; $10 \mathrm{~min} ; 1500 \mathrm{rpm}$ ). Pellets were resuspended in $300 \mu \mathrm{l}$ of hypotonic staining buffer containing $0.02 \mathrm{mg} / \mathrm{ml}$ propidium iodide and incubated on ice for $30 \mathrm{~min}$. Flow cytometry was performed (FACS Calibur, Becton Dickinson, Heidelberg, Germany) by using Cell Quest ${ }^{\mathrm{TM}}$ software.

\section{RNA interference}

HepG2 cells were transfected in 24 -well plates $\left(7.5 \times 10^{4}\right.$ cells/ well) using Lipofectamine RNAiMax (Invitrogen, Karlsruhe, 
Germany). A set of four predesigned small interfering RNAs (siRNAs; Qiagen, Hilden, Germany) matching human FLIP RNA was transfected (final concentration $25 \mathrm{nmol} / \mathrm{l}$ ). A further set of four siRNA sequences without homology to any known mammalian RNA was applied as a negative control. All values were referred to untreated control cells (\% control).

\section{Real-time cell proliferation assay}

HepG2 cells $\left(5 \times 10^{3}\right.$ cells/well) were seeded in 96-well plates (E-Plate 96, Roche Applied Science, Mannheim, Germany). Realtime dynamic cell proliferation was monitored at $2 \mathrm{~h}$ intervals during $48 \mathrm{~h}$ using the xCELLigence system (Roche Applied Science). Cell index values were calculated using the RTCA Software (1.0.0.0805). All curves were normalised at the beginning of the treatment period applying the RTCA Software. ${ }^{23} 24$

\section{Human tissue slicing}

Human liver resections from three donor patients were obtained from the Department of General, Visceral and Transplant Surgery, University Clinic Tuebingen, according to the guidelines of the local Ethics Committee with informed consent. Precisioncut liver slices were prepared as described in the Supplementary Materials and methods section online.

\section{CAM assay}

CAM assay was done as described previously. ${ }^{25}{ }^{26}$ Briefly, $1 \times 10^{6}$ HepG2 cells were implanted on fertilised chicken eggs on day 8 of incubation and were treated with $5 \mu \mathrm{mol} / \mathrm{l} 5$-aza-CR and/or $100 \mathrm{ng} / \mathrm{ml}$ TRAIL for 4 days, sampled with the surrounding CAM, fixed in $4 \%$ paraformaldehyde, paraffin embedded, cut in $5 \mu \mathrm{m}$ sections and histologically analysed using 1:1 haematoxylin and $0.5 \%$ eosin. Images were digitally recorded at a magnification of $\times 2$ with an $A \times 70$ microscope (Olympus, Center Valley, Pennsylvania, USA). Tumour areas were analysed with ImageJ digital imaging software (download from the NIH website, http://rsbweb.nih.gov/ij/download.html).

\section{Statistical analysis}

Statistical analyses were performed with either Student $t$ test or one-way analysis of variance (ANOVA) Bonferroni post-test using GraphPad Prism version 4.00 (GraphPad Software, San Diego, California, USA). A p value of $<0.001$ is indicated in the figures by an asterisk.

\section{RESULTS}

\section{5-Aza-CR but not 5 -aza-dC mediates a rapid sensitisation of hepatoma cells to TRAIL}

Combined short-term $(24 \mathrm{~h})$ incubation of TRAIL-resistant HepG2 human hepatoblastoma cells with 5-aza-CR and TRAIL revealed a significant increase of apoptosis as indicated by propidium iodide-positive cells in sub2N-DNA FACS quantification (figure 1A; time course in the upper figure, statistical analysis at $24 \mathrm{~h}$ in the lower figure). In contrast, no apparant change was observed under combined treatment with 5-aza-dC and TRAIL or monotherapeutic application of either substance alone.

To reassess these results, the effects of 5-aza-CR and 5-aza-dC were further studied by fluorescein diacetate assays, now additionally employing the hepatoma cell line Hep3B (figure 1B). Again, a combined treatment with 5-aza-CR and TRAIL induced a highly significant decline in the number of both HepG2 and Hep3B cells of $>50 \%$, whereas 5 -aza-dC again was not able to overcome resistance to TRAIL; also monotherapeutic application of either substance alone did not lead to any reduction in hepatoma cell survival.
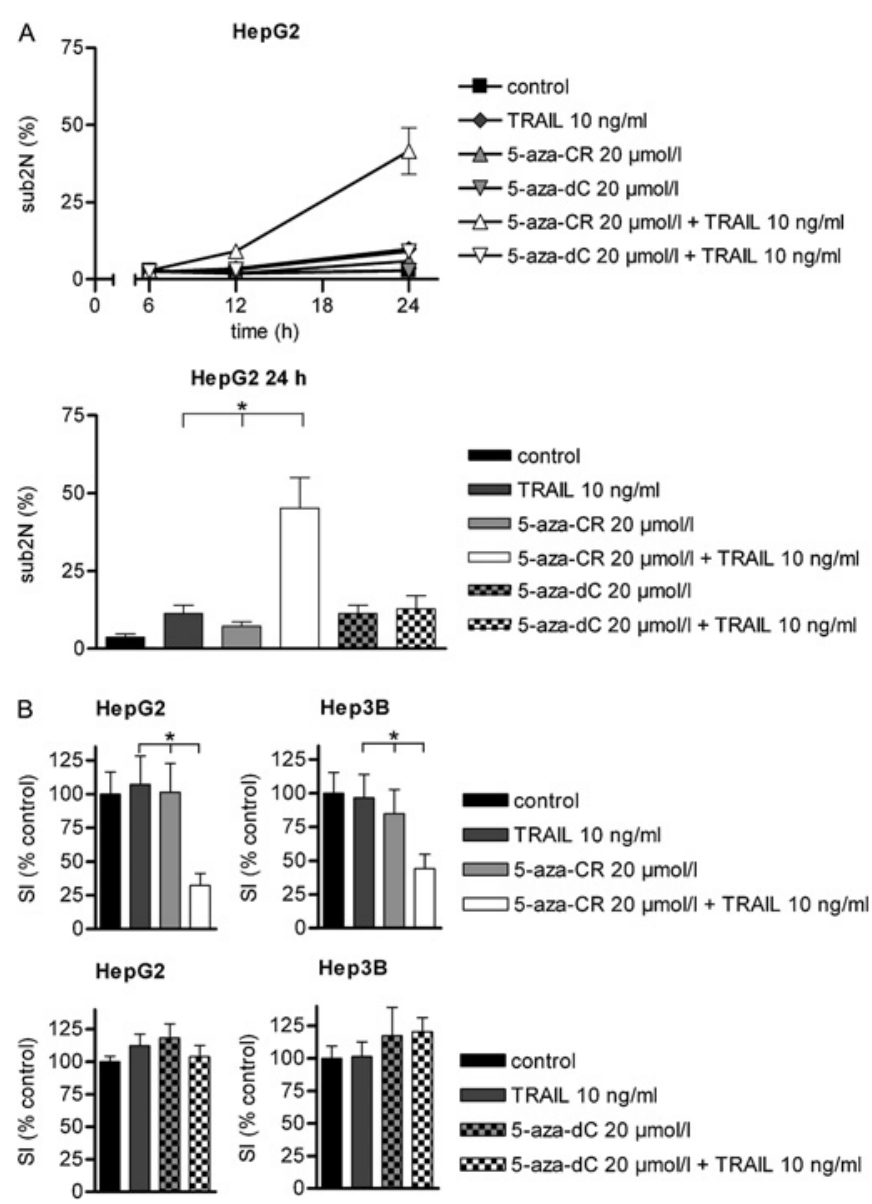

control
TRAIL $10 \mathrm{ng} / \mathrm{ml}$
5 -aza-dC $20 \mu \mathrm{mol} /$

Figure 1 Tumour necrosis factor-related apoptosis-inducing ligand (TRAIL) in combination with 5-azacytidine (5-aza-CR), but not with 5-aza-2 ${ }^{\prime}$-deoxycytidine (5-aza-dC), induces cell death in human-derived hepatoma cells. (A) HepG2 hepatoblastoma cells were incubated with $20 \mu \mathrm{mol} / / 5$-aza-CR or $20 \mu \mathrm{mol} / \mathrm{l} 5$-aza-dC and/or $10 \mathrm{ng} / \mathrm{ml}$ TRAIL (upper diagram). After 6, 12 and $24 \mathrm{~h}$, cells were stained with propidium iodide and the fraction of apoptotic cells was determined by fluorescenceactivated cell sorting (FACS) analysis (sub2N-DNA). Statistical analysis was performed at $24 \mathrm{~h}$ (lower diagram); shown are here the mean of three independent experiments \pm SD. (B) HepG2 and Hep3B cells were treated for $24 \mathrm{~h}$ with either $20 \mu \mathrm{mol} / \mathrm{l} 5$-aza-CR, $20 \mu \mathrm{mol} / / \mathrm{l}$-aza-dC and $10 \mathrm{ng} / \mathrm{ml}$ TRAlL alone or the combination thereof. Cell survival was investigated by fluorescein diacetate assay. All values (\% control) were referred to untreated control cells. Shown are the mean of three independent experiments $\pm S D$. $(A, B){ }^{*} p<0.001$, one-way analysis of variance Bonferroni post-test; significance is indicated where the combination treatment of 5-aza-CR and TRAIL was more efficient than each treatment alone.

Based on the observation that 5 -aza-CR but not 5 -aza-dC possesses the ability to sensitise hepatoma cells to TRAIL within a short incubation period not exceeding $24 \mathrm{~h}$, we hypothesised that DNMT inhibition, which is known to require much more 'effector time', 1819 could not be the molecular mechanism responsible for this effect. Thus, we assumed that the earlier described additional inherent activity of 5-aza-CR in inhibiting protein synthesis ${ }^{9-11}$ might be the main mechanism responsible for this rapid sensitisation to TRAIL.

General inhibition of protein biosynthesis by 5-aza-CR or CHX induces a downregulation of the antiapoptotic factor FLIP $_{\mathbf{L}}$

CHX is well known to block translational elongation, resulting in a reversible inhibition of protein biosynthesis at the ribosomal level, comparable with the effects of 5-aza-CR. 
To further support the hypothesis of an inhibition of protein synthesis by 5 -aza-CR in hepatoma cells, we next performed a flow cytometry-based analysis of HepG2 cells transiently transfected with the enhanced green fluorescent protein (EGFP) reporter gene. Again, within only $24 \mathrm{~h}$, we found a dosedependent shut-down of EGFP expression mediated by both compounds, CHX or 5-aza-CR, but not by 5-aza-dC (figure 2A). Of note, the combined treatment of both cell lines, HepG2 and Hep3B, with CHX and TRAIL (figure 2B) was found to yield a decline in the surviving cell fraction similar to the results of the incubation with 5-aza-CR and TRAIL (figure 1B), whereas no significant reduction was observed under monotherapy with CHX or TRAIL alone.

It has been shown that CHX treatment of hepatoma cells results in a reduction of the intracellular level of the antiapoptotic FLIP, and that FLIP downregulation is able to sensitise for high doses of TRAIL $(100 \mathrm{ng} / \mathrm{ml}){ }^{27}$ Thus, it was of interest whether CHX and 5-aza-CR share a common mechanism regarding FLIP, which was examined by a western blot analysis (figure $2 \mathrm{C}$ ). In line with the pattern of reaction to CHX, treatment with 5-aza-CR resulted in a clear reduction of the intracellular concentration of the long form of FLIP (FLIP $\mathrm{L}_{\mathrm{L}}$ ).
Incubation of HepG2 cells with different concentrations of 5 -aza-dC had no comparable effect on FLIP $_{L}$ (Supplementary figure $1 \mathrm{~A}$ online). In addition, the 5-aza-CR-mediated downregulation of protein synthesis seems also to affect other important cellular proteins such as p53 (Supplementary figure 1B online).

To functionally verify the importance of FLIP $_{\mathrm{L}}$ in our setting specifically applying low doses of TRAIL (10 ng/ml), a specific knockdown of endogenous FLIP in HepG2 cells was performed via transfection of FLIP siRNA (figure 2D). Interestingly, this singular knockdown of FLIP was able to induce a significant sensitisation towards TRAIL-mediated cytotoxicity, whereas the control transfection with a set of non-coding siRNAs and co-treatment with TRAIL did not show an increase in lactate dehydrogenase $(\mathrm{LDH})$ release as a surrogate parameter for toxicity (figure 2D). Notably, the combined incubation of 5-aza$\mathrm{CR}$ and TRAIL led to a similar increase in $\mathrm{LDH}$ release which could not be further enhanced by siRNA-mediated inhibition of FLIP (figure 2D, white bars). It is concluded from these experiments that downregulation of FLIP $_{L}$ by 5 -aza-CR or CHX can be regarded as a major mechanism to overcome TRAIL resistance in human hepatoma cells.
A
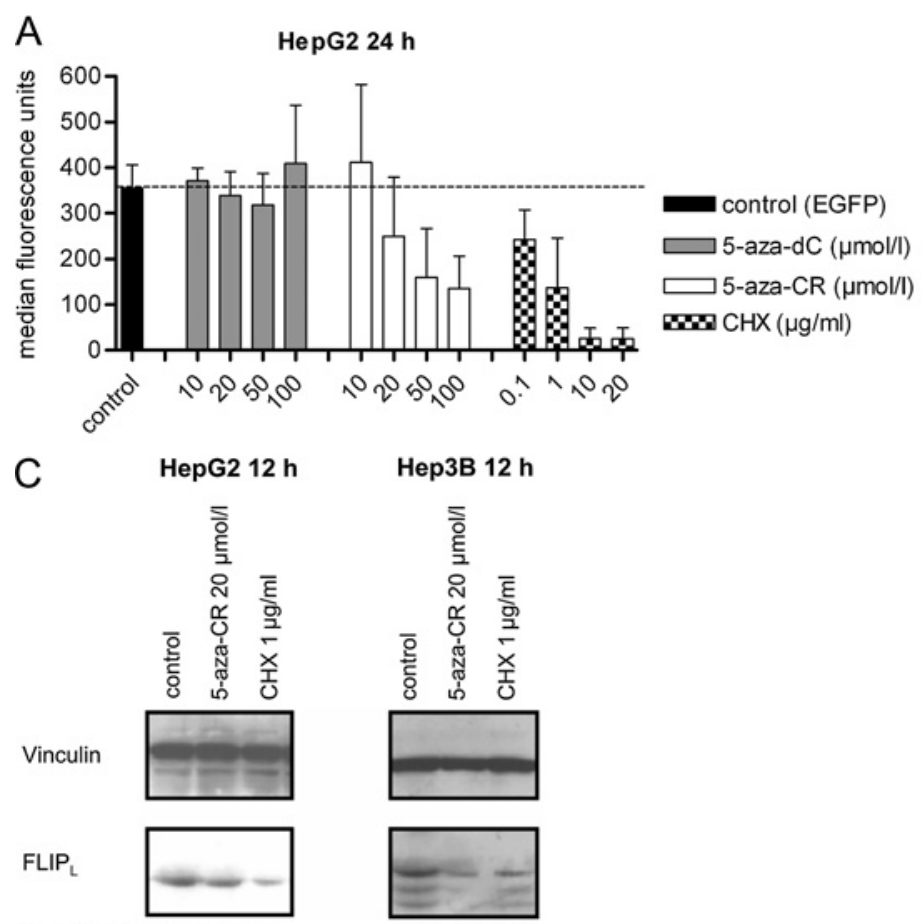

Rel \% FLIP 1006625

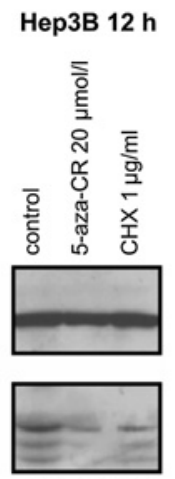

$100 \quad 57 \quad 36$
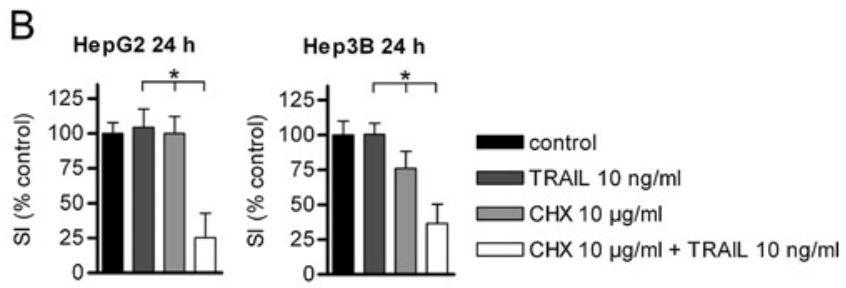

Figure 2 Hepatoma cell sensitisation to tumour necrosis factor-related apoptosis-inducing ligand (TRAIL) by inhibition of protein synthesis and reduction of intracellular levels of FLICE inhibitory protein (FLIP). (A) The decrease of enhanced green fluorescent protein (EGFP) fluorescence by inhibition of protein translation displayed as median fluorescent intensity of HepG2 cells transiently transfected with EGFP and simultaneously treated with increasing concentrations of either 5 -aza-2' -deoxycytidine (5-aza-dC), 5-azacytidine (5-aza-CR) or cycloheximide (CHX). The cell population marked as EGFP served as the control. Fluorescence-associated cell sorting (FACS)-based analysis on the intensity of emerging fluorescence was performed $24 \mathrm{~h}$ after transfection. Shown are means of three independent experiments \pm SD. (B) HepG2 and Hep3B cells were cultured in the presence or absence of $10 \mathrm{ng} / \mathrm{ml} \mathrm{TRAIL} \mathrm{and/or} 10 \mu \mathrm{g} / \mathrm{ml} \mathrm{CHX.} \mathrm{Cell} \mathrm{survival} \mathrm{was} \mathrm{detected} \mathrm{by} \mathrm{fluorescein} \mathrm{diacetate} \mathrm{assay.} \mathrm{All} \mathrm{values} \mathrm{were} \mathrm{referred} \mathrm{to} \mathrm{untreated}$ control cells (\% control). Shown are the mean of three independent experiments \pm SD. ${ }^{*} p<0.001$, one-way analysis of variance (ANOVA) Bonferroni post-test with a significance of the combinatorial treatment being more efficient than each treatment alone. (C) FLIP $\mathrm{P}_{\mathrm{L}}$ expression in HepG2 and Hep3B cells after incubation with $20 \mu \mathrm{mol} / \mathrm{l} 5$-aza-CR or $1 \mu \mathrm{g} / \mathrm{ml} \mathrm{CHX}$ for $12 \mathrm{~h}$ was examined by western blot analysis. Equal protein loading was verified by vinculin staining on the same blot (upper band). FLIP ${ }_{L}$ levels were estimated by performing a densitometric analysis; values are shown relative to untreated controls. (D) HepG2 cells were transfected with either a set of non-coding control small interfering RNA (siRNA; NC) or FLIP-targeted siRNA (FLIP). At $48 \mathrm{~h}$ after transfection cells were incubated for $24 \mathrm{~h}$ with $20 \mu \mathrm{mol} / \mathrm{l} 5$-aza-CR and/or $10 \mathrm{ng} / \mathrm{ml}$ TRAlL. Cytotoxicity was investigated by measurement of relative lactate dehydrogenase (LDH) release; all values were referred to untreated control cells (\% control). Shown are the mean of three independent experiments $\pm \mathrm{SD}$. ${ }^{*} \mathrm{p}<0.001$, one-way ANOVA Bonferroni post-test, n.s., no significant difference. 


\section{Dual antitumour effect of 5-aza-CR and TRAIL by an early caspase activation followed by an inhibition of cellular proliferation in surviving tumour cells}

Epigenetic treatment of cancer cells based on drugs that alter the methylation pattern in tumour cells by DNMT inhibition are generally thought to require at least one replication round of the tumour cells before therapeutic effects occur. ${ }^{818} 19$ According to our results in hepatoma cells, therapeutic combination of 5-azaCR with TRAIL habours a dual antitumour activity, based on (1) a rapid induction of apoptotic cell death, independent of an epigenetic modulation, followed by (2) an alteration of methylation events in surviving cancer cells in combination with an enduring suppression of cellular protein synthesis. To support this hypothesis further, time course experiments of both caspase activation and cellular proliferation were performed.

Caspase activation was investigated for the initiator caspase- 8 and the executioner caspase-3/7 by fluorimetric caspase activity assays (figure $3 \mathrm{~A}, \mathrm{~B}$ ). Already after $6 \mathrm{~h}$, but more pronounced after $12 \mathrm{~h}$ of combined treatment with 5-aza-CR and TRAIL, a significant induction of caspase-8 (figure $3 \mathrm{~A}$ ) and caspase-3/7 (figure $3 \mathrm{~B}$ ) could be detected. This increase of activation was already terminated within the first $24 \mathrm{~h}$ of treatment. Incubation with 5-aza-CR or TRAIL alone did not show any relevant caspase activity at any point in time. Notably, incubation with STS, a rapid and strong inducer of apoptosis in hepatoma cells, ${ }^{28}$ showed a similar reaction pattern with only marginally higher caspase activity values. Additional real-time monitoring of caspase-3 activity within live cells after $12 \mathrm{~h}$ of treatment also demonstrated caspase activation after co-treatment, but not by incubation with each substance alone (Supplementary figure 2 online).

To monitor cellular proliferation in real-time under various treatment schedules, the $\mathrm{xCELLigence^{ \textrm {TM } }}$ system was used (figure $3 \mathrm{C}$ ) to obtain cell index curves by a continuous measure- ment of the electrode impedance in each well. This parameter reflects the biological status of the cell layer, including cell viability and proliferation, and is depicted by the normalised cell index. ${ }^{23}{ }^{24}$ Combination treatment of 5-aza-CR and TRAIL induced a rapid and substantial reduction of the normalised cell index, occurring within a $6-12 \mathrm{~h}$ time span (figure 3C). In contrast, HepG2 cells treated with 5-aza-CR alone or TRAIL alone displayed a $24 \mathrm{~h}$ proliferation pattern quite similar to that of untreated control cells. Between 24 and $48 \mathrm{~h}$, a reduced proliferation signal could be detected for 5-aza-CR-treated cells, which most probably reflects the well-known kinetics of epigenetic modulation due to DNMT inhibition together with ongoing inhibition of cellular protein synthesis (figure $3 \mathrm{C}$ ). As a positive control for cell death, detergent treatment with Triton X-100 induced a direct and very rapid decline in the normalised cell index. Thus, after a rapid decline due to 5-aza-CR-mediated sensitisation to TRAIL, surviving hepatoma cells are then exposed to 5-aza-CR's dual effects of DNMT and protein biosynthesis inhibition, imposing a second hit on the hepatoma cells.

\section{Lack of toxicity of the combination of 5-aza-CR and TRAIL for non-malignant cell types}

To minimise unwanted side effects that might limit translation of new treatment strategies into clinical applications, toxicity studies are inevitable. Especially in the context of the liver, each new application strategy employing TRAIL has to be carefully tested for its potential liver toxicity. Thus, we employed PHHs and human-derived liver tissue cultures, so-called precision-cut liver slices ${ }^{29}$ to investigate both (1) cellular integrity of nonmalignant cells and (2) severity of cellular damage by $\mathrm{LDH}$ and aspartate aminotransferase (AST) release assays.

Applying two different doses of TRAIL (10 and $100 \mathrm{ng} / \mathrm{ml}$ ), a strong increase of $\mathrm{LDH}$ and AST release into the supernatant during combined 5-aza-CR and TRAIL treatment was found in
Figure 3 Time course of caspase activation and real-time measurement of cellular proliferation. (A, B) HepG2 cells were treated with $20 \mu \mathrm{mol} / \mathrm{l}$ 5-azacytidine (5-aza-CR) and/or $10 \mathrm{ng} / \mathrm{ml}$ tumour necrosis factor-related apoptosis-inducing ligand (TRAIL); staurosporine (STS) was used as a positive control. (A) Initiator caspase8 and (B) effector caspase-3/7 activities were determined after 6,12 and $24 \mathrm{~h}$ of treatment. Shown are the mean of three independent experiments. ${ }^{*} p<0.001$, one-way analysis of variance Bonferroni post-test; significance of caspase- 8 and caspase- $3 / 7$ activation is indicated where the combination of 5-aza-CR and TRAIL was more efficient than each treatment alone. (C) Real-time analysis of cell proliferation by a continuous measurement of the electrode impedance in each well using the $x^{x}$ CELLigence ${ }^{T M}$ system. HepG2 cells were treated over $48 \mathrm{~h}$ with $20 \mu \mathrm{mol} / \mathrm{l}$ 5-aza-CR and/or $10 \mathrm{ng} / \mathrm{ml}$ TRAIL. As a positive control $0.1 \%$ Triton X-100 was used. All values were normalised to an initial time point. $0 \mathrm{~h}$ represents the beginning of the treatment. Shown are the mean values of the normalised cell index of three independent experiments.
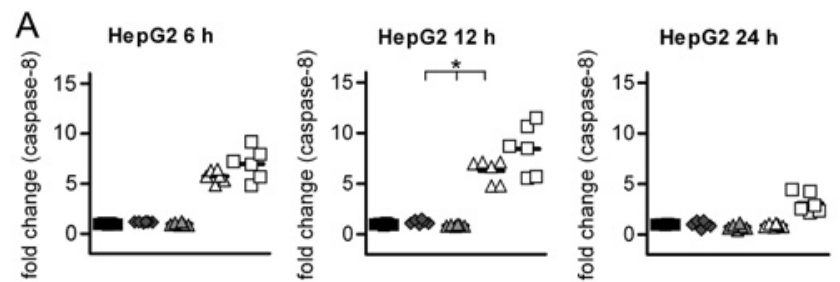

- control

- TRAll $10 \mathrm{ng} / \mathrm{ml}$

$\Delta$ 5-aza-CR $20 \mu \mathrm{mol} / \mathrm{l}$

$\Delta$ 5-aza-CR $20 \mu \mathrm{mol} / \mathrm{l}+$ TRAll $10 \mathrm{ng} / \mathrm{ml}$ STS $5 \mu \mathrm{mol} / \mathrm{l}$
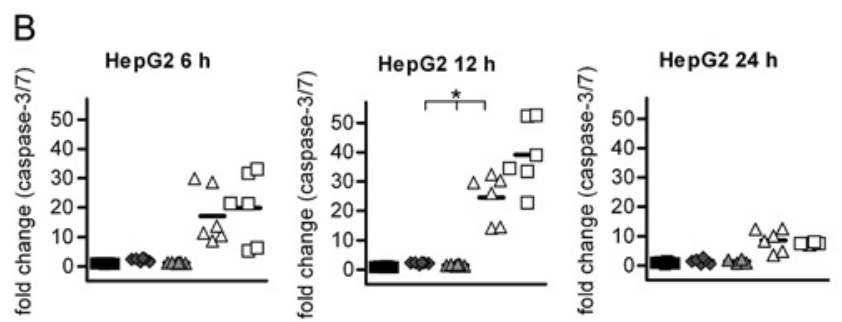

- control

- TRAIL $10 \mathrm{ng} / \mathrm{ml}$

$\triangle$ 5-aza-CR $20 \mu \mathrm{mol} / \mathrm{l}$

$\Delta$ 5-aza-CR $20 \mu \mathrm{mol} / \mathrm{l}+$ TRAll $10 \mathrm{ng} / \mathrm{ml}$

․ STS $5 \mu \mathrm{mol} / \mathrm{l}$




Figure 4 Lack of toxicity of 5 -azacytidine (5-aza-CR) in combination with tumour necrosis factor-related apoptosis-inducing ligand (TRAIL) on primary human hepatocytes or humanderived liver tissue slices. HepG2 cells, primary human hepatocytes (PHHs) and precision-cut liver slices from three different donors (PHH and liver slices) were incubated for $24 \mathrm{~h}$ with $20 \mu \mathrm{mol} / \mathrm{l}$ 5-aza-CR and/or $100 \mathrm{ng} / \mathrm{ml}$ TRAlL. Release of $(A)$ lactate dehydrogenase (LDH) or (B) aspartate aminotransferase (AST) into the supernatant was analysed by ELISA. All values were referred to untreated cells (\% control).
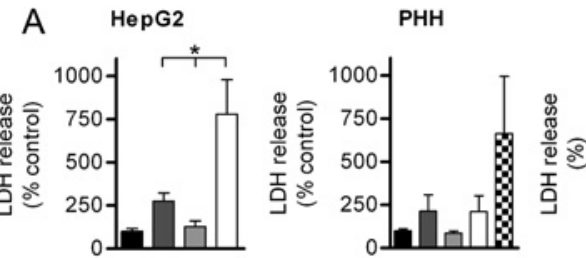

liver slice




liver slice toxicity could be detected for the combinatorial treatment of PHHs or liver slices.

HepG2 hepatoblastoma cells at both concentrations (figure 4 and Supplementary figure 3 online). In contrast, human-derived liver slices from different donors did not show significant increases of AST or LDH release, even under employment of high doses of TRAIL (figure 4).

The 5-aza-CR-mediated sensitisation of tumour cells to TRAIL occurred at $10 \mathrm{ng} / \mathrm{ml}$. At this concentration no toxic effect could be detected in $\mathrm{PHH}$ concerning the release of $\mathrm{LDH}$ or AST (Supplementary figure 3 online). Employing a fluorescein diacetate assay, PHHs did not show a reduced survival under $10 \mathrm{ng} / \mathrm{ml}$ TRAIL and $20 \mu \mathrm{mol} / \mathrm{l}$ 5-aza-CR (figure 5A, left side). Using an SRB assay, which measures cellular protein content as a surrogate marker for viability, 5-aza-CR in combination with TRAIL was not different from TRAIL treatment alone in PHHs (figure 5, right side). However, a slight reduction of the $\mathrm{PHH}$ viability was detected in each sample with TRAIL. Neither LDH nor AST release was increased in PHHs under these treatment conditions (Supplementary figure 3 online), which excluded a substantial toxicity of the treatments. Even employing a 10-fold increased concentration of TRAIL, no AST and only a slight but not significant ( $p>0.05$, one-way ANOVA Bonferroni post-test) $\mathrm{LDH}$ release from $\mathrm{PHH}$ occurred (figure $4 \mathrm{~A}$, middle graphs). Treatment with Triton X-100 was used for PHHs or liver slices as a surrogate marker to determine the maximum obtainable amount of $\mathrm{LDH}$ or AST release, thereby reflecting the heterogeneity of different liver sample donors with different clinical histories. Taken together we conclude that 5 -aza-CR is not mediating a sensitisation of non-malignant liver cells to TRAIL, even with high concentrations of TRAIL.

Next, a possible activation of executioner caspases in $\mathrm{PHH}$ under 5-aza-CR and TRAIL co-treatment was investigated. In clear contrast to the previous experiments (figure $3 \mathrm{~B}$ ), no increase of caspase activity could be detected in PHHs at any point in time, whereas incubation with STS as a positive control
Figure 5 Pattern of reaction of primary human hepatoytes ( $\mathrm{PHH}$ ) to combined treatment with 5-azacytidine (5-aza-CR) and tumour necrosis factorrelated apoptosis-inducing ligand (TRAIL) (A) PHHs from three different donors were incubated with $20 \mu \mathrm{mol} / \mathrm{l}$ 5 -aza-CR and/or $10 \mathrm{ng} / \mathrm{ml}$ TRAIL. Cell survival was determined in a fluorescein diacetate assay (left graph). The same PHHs were used for a sulforhodamine B assay to prove cell viability (right graph). The mean of three independent experiments $\pm S D$ are shown. (B) Caspase- $3 / 7$ activity was investigated 6,12 and $24 \mathrm{~h}$ after the initiation of the indicated treatments. Staurosporine (STS; $5 \mu \mathrm{mol} / \mathrm{l}$ ) was used as a positive control. (A, B) No statistical significant toxicity in the $(A)$ fluorescein diacetate assay or (B) caspase activation could be detected for the combinatorial treatment of PHHs by a one-way analysis of variance Bonferroni post test. (C) Western blot analysis to assess the amount of the long form of FLICE inhibitory protein $\left(\mathrm{FLIP}_{\mathrm{L}}\right)$ in $\mathrm{PHH}$ cellular lysates at different points in time. Equal protein loading was verified by vinculin staining (upper band).
A PHH $24 \mathrm{~h}$
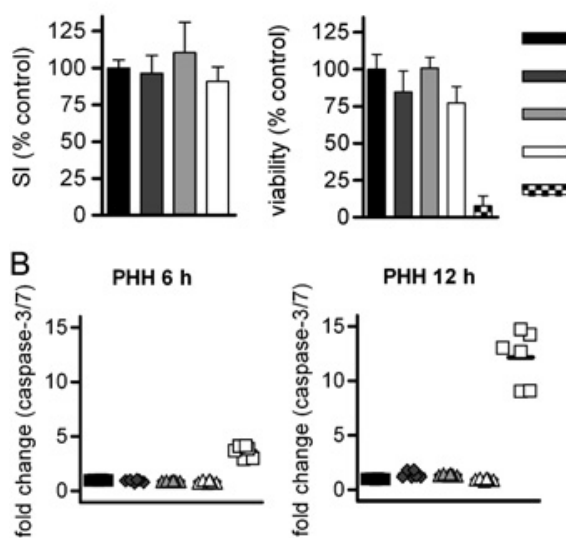

C


control

TRAIL $10 \mathrm{ng} / \mathrm{ml}$

5-aza-CR $20 \mu \mathrm{mol} / \mathrm{l}$

5-aza-CR $20 \mu \mathrm{mol} / \mathrm{l}+$ TRAIL $10 \mathrm{ng} / \mathrm{ml}$

$\Leftrightarrow$ Triton X-100 1\%
PHH 24 h

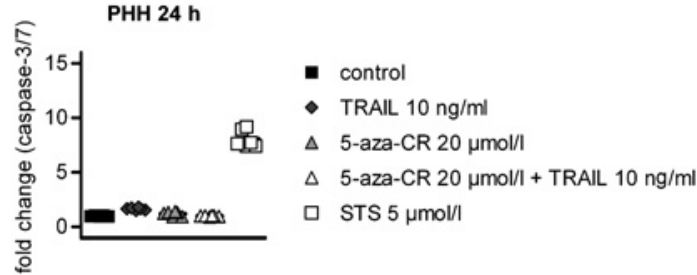

PHH 24 h 
for apoptosis induction clearly induced caspase activity up to 12-fold (figure 5B). Finally, we examined whether the treatment of PHHs with 5-aza-CR has any influence on intracellular FLIP $_{\mathrm{L}}$ protein levels. In contrast to the cell lines HepG2 and Hep3B (figure 2C), PHHs showed no alteration of the $\mathrm{FLIP}_{\mathrm{L}}$ protein level either under 5-aza-CR or CHX treatment at any point in time (figure 5C).

To further evaluate possible toxic effects in another nonmalignant tissue context, two non-malignant colon cell lines CCD-18Co (Supplementary figures 4 and 5 online) and CCD $841 \mathrm{CoN}$ (Supplementary figures 6 and 7 online) were investigated using 10 and $100 \mathrm{ng} / \mathrm{ml}$ TRAIL. With the exception of caspase-3/7 activity in CCD $841 \mathrm{CoN}$ cells incubated with the high concentration of TRAIL $(100 \mathrm{ng} / \mathrm{ml})$ or the combination of TRAIL and 5-aza-CR, no signs of toxicity could be detected in viability assays, $\mathrm{LDH}$ release or caspase-3/7 activation.

\section{In vivo activity of 5-aza-CR and TRAIL}

Subsequently, the in vitro characterised treatment schedules were further investigated in vivo in a CAM assay with HepG2 cells (figure 6). Representative images of the H\&E-stained sections demonstrate a profound reduction of the tumour mass mediated by combined 5-aza-CR and TRAIL treatment, whereas either monotherapeutic approach had no relevant effect on the tumour size (figure 6A). For statistical evaluation, sections were digitally recorded and tumour areas were analysed (figure 6B). In line with our previous in vitro experiments, the combinatorial treatment group was found to be statistically significantly different from each single and the untreated control group. Thus, a clear effectiveness of combined 5-aza-CR and TRAIL treatment was also demonstrated in an in vivo model.

\section{5-Aza-CR-mediated TRAIL sensitisation can be expanded to renal, pancreatic and colon cancer cells}

The sensitisation of TRAIL-resistant tumour cells by CHX has been described for other tumour entities, too. Therefore, it was reasonable to assume, that the observed TRAIL sensitisation by 5 -aza-CR in hepatoma cells might be a more general mechanism.

To address this question, we also studied viability, survival and caspase activity in the renal cancer cell (RCC) line A-498, which is included in the NCI60 human tumour cell line panel. A-498 is known to exhibit a resistance to TRAIL-induced apoptosis, which can be overcome by a knockdown of FLIP. ${ }^{30}$ We detected a significant decline of both the viability and cellular survival after a short incubation with 5-aza-CR and TRAIL (figure 7A). In comparison, treatment with 5 -aza-dC did not sensitise for TRAIL (figure 7B), but the established protein synthesis inhibitor CHX did (figure 7C). Furthermore, in analogy to the caspase activation in HepG2 cells, the activation of caspases in A-498 cells was examined at an early time point $(12 \mathrm{~h})$ after initiation of treatment (figure 7D). Activities of both the initiator caspase8 and the executioner caspase-3/7 were found to be significantly elevated, while incubation with 5 -aza-CR or TRAIL alone did not show any relevant activity. These observations could be expanded to pancreatic cancer cells MIA PaCa-2 (Supplementary figure 8 online) as well as colon cancer cells HCT-116 and COLO 205 (Supplementary figures 9 and 10 online). Taken together, the concept of 5-aza-CR's dual activity enabling TRAIL resistance to be overcome could be regarded as a general mechanism in different tumour entities.

\section{DISCUSSION}

Human hepatoma cells display a marked resistance to conventional cytostatic agents, with the exception of the oral
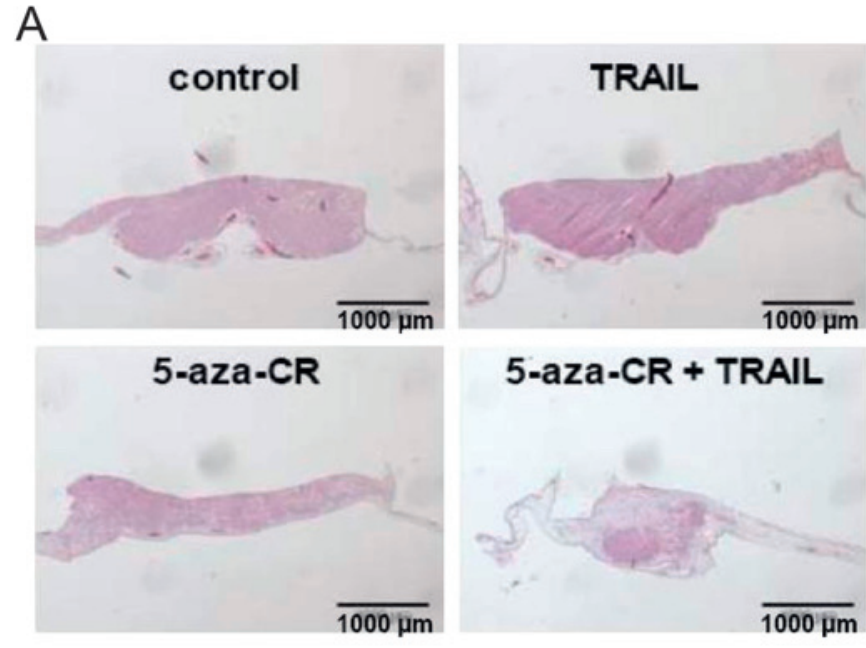

5-aza-CR + TRAIL

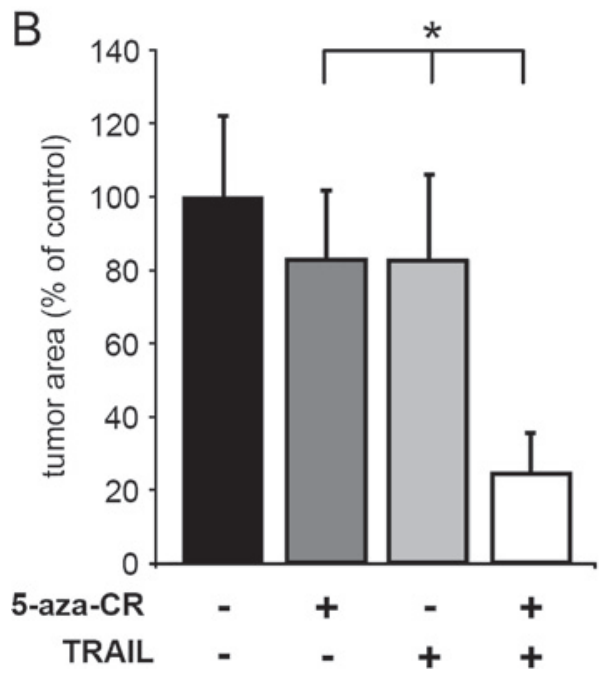

Figure 6 In vivo sensitisation to tumour necrosis factor-related apoptosis-inducing ligand (TRAIL)-induced cell death by 5 -azacytidine (5-aza-CR). (A, B) HepG2 cells were seeded on the chorioallantoic membrane (CAM) of chicken embryos and treated with $5 \mu \mathrm{mol} / \mathrm{l}$ 5 -aza-CR and/or $100 \mathrm{ng} / \mathrm{ml}$ TRAlL. Tumour growth was analysed using H\&E-stained paraffin sections of the CAM. Representative pictures of H\&E-stained sections of the CAM (A) and measured tumour area (B) are shown. Error bars indicate the means $\pm S D$ of nine samples per group from two independent experiments. ${ }^{*} p<0.001$, Student $t$ test.

multikinase inhibitor sorafenib, ${ }^{2}$ but still alternative therapy strategies are urgently needed. ${ }^{31}$

In the present study, we succeeded in overcoming the resistance to TRAIL in vitro and in vivo by using 5-aza-CR, one of the currently most advanced drugs for epigenetic cancer treatment. ${ }^{8}$ Most strikingly, 5-aza-CR was found to restore sensitivity to TRAIL in tumour cells very quickly (within $24 \mathrm{~h}$ ) and effectively. Importantly, the combined 5-aza-CR/TRAIL treatment exhibited no toxic effect in human-derived primary hepatocytes and liver tissue slices from different donors or non-malignant colon cell lines. Furthermore, we were able to find several lines of evidence that this rapid sensitisation to TRAIL is not mediated via epigenetic mechanisms, but due to a currently rarely discussed, but well-known 'side' effect of 5-aza-CR-that is, the reversible disruption of cellular protein biosynthesis. The intracellular metabolisation and mode of action as well as the TRAIL signal transduction are summarised in figure 8.

In contrast, the closely related compound 5 -aza-dC possesses a deoxyribose backbone, which excludes the possibility of 
Figure 7 5-Azacytidine (5-aza-CR)mediated sensitisation of renal cancer cells to tumour necrosis factor-related apoptosis-inducing ligand (TRAIL)induced apoptosis. (A, B) A-498 renal cell carcinoma (RCC) cells were incubated with (A) $20 \mu \mathrm{mol} / / 5$-aza-CR and (B) $20 \mu \mathrm{mol} / \mathrm{l}$ 5-aza- $2^{\prime}$ deoxycytidine (5-aza-dC) and/or $10 \mathrm{ng} /$ $\mathrm{ml}$ TRAIL. A fluorescein diacetate assay to detect cell survival was performed (left graph). Cell viability was determined in a sulforhodamine B assay (right graph), with $100 \%$ viability representing the optical density of untreated cells. (C) The same experimental set-up but with $10 \mu \mathrm{g} / \mathrm{ml}$ cycloheximide (CHX) instead of 5-azaCR to determine survival and viability of the cells was used. (D) Caspase-8 (left graph) and caspase-3/7 activity (right graph) was investigated $12 \mathrm{~h}$ after the initiation of the treatment. Staurosporine (STS; $5 \mu \mathrm{mol} / \mathrm{l}$ ) was used as a positive control. $(A-D)$ The means of three independent experiments $(A-C) \pm S D$ are shown. ${ }^{*} p<0.001$, one-way analysis of variance Bonferroni post-test; significance is indicated where the combination treatment of 5-aza-CR and TRAIL was more efficient than each treatment alone.
A $\quad$ A-498 $24 \mathrm{~h}$

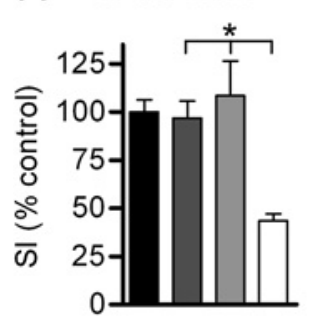

B $\quad$ A-498 $24 \mathrm{~h}$

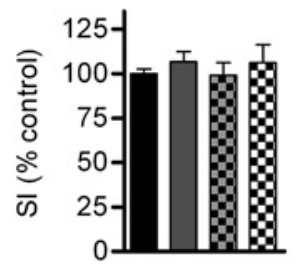

C $\quad$ A-498 $24 \mathrm{~h}$
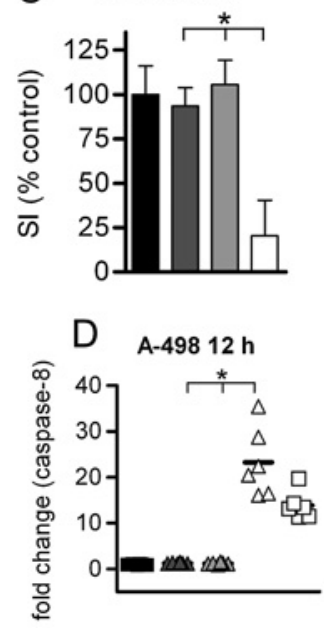

A-498 $24 \mathrm{~h}$

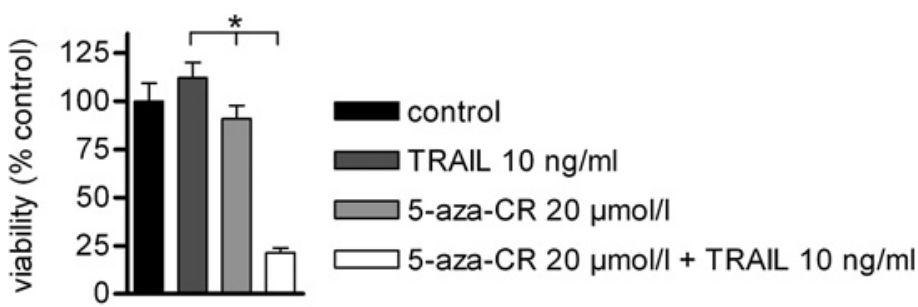

A-498 $24 h$



A-498 $24 \mathrm{~h}$
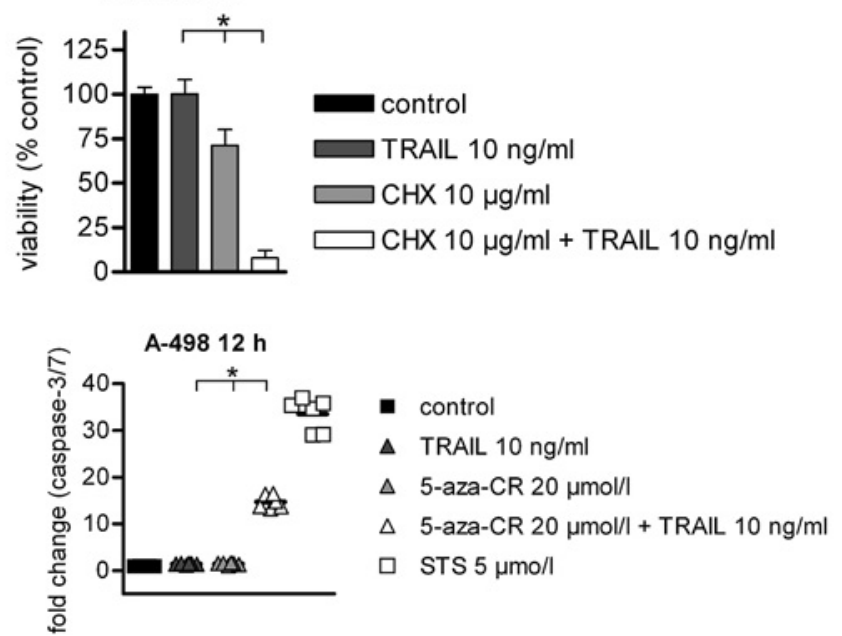

incorporation into cellular RNA and subsequent disruption of cellular protein biosynthesis. This differential feature is one of the main reasons why 5 -aza-CR is clinically regarded as the more toxic DNMT inhibitor compound. Furthermore, 5-aza-CR only exhibits a poor conversion rate into its DNMT-inhibiting deoxyribonucleotide form, ${ }^{8}$ resulting in a less potent inhibition of cellular DNMTs than found for similar concentrations of 5 -aza-dC. For both reasons, 5-aza-dC currently is the most established substance among the DNMT inhibitor compound family. Taking this into account, it is not surprising that present studies on the combination of TRAIL and DNMT inhibitor compounds focus almost exclusively on the usage of 5-aza-dC, for instance in breast cancer, glioblastoma or neuroblastoma. ${ }^{18-20}$ Hence, studies which applied 5-aza-dC in the context of TRAIL sensitisation have been prone to miss the early effect of a decrease in regulatory cellular proteins.

In line with our result of a 5-aza-CR-mediated sensitisation to TRAIL, a recent report focusing on death receptor-induced apoptosis in general describes a sensitisation by 5 -aza-CR towards death receptor-induced apoptosis. ${ }^{21}$ However, from a clinical perspective there are two major limitations of this work that would interfere substantially with a clinical translation of our suggested approach. First, a rapid killing of PHHs from a single donor under the combination treatment was reported, but in this case an artificially tagged TRAIL preparation had been

applied which had been attributed to an enhanced toxicity in primary cells in previous studies. ${ }^{32}{ }^{33}$ Secondly, the authors suggested that TRAIL sensitisation might be p53 dependent, which would be highly relevant due to the fact that the p53 pathway is impaired in the majority of HCC. ${ }^{34}$ In contrast to that hypothesis, we detected a significant reduction of cell survival for the different tumour cell lines Hep3B, MIA PaCa-2 and COLO 205, when treated with 5-aza-CR and TRAIL. This is most important, because the hepatoma cell line Hep3B is known to be p53 deficient, whereas MIA PaCa-2 and COLO 205 have a mutated p53..$^{35-37}$ Moreover, p53 is a cellular protein with a short half-life of only $15-20$ min. ${ }^{38}$ Due to the rapid breakdown of protein biosynthesis by 5 -aza-CR treatment, we detected a decline in the p53 levels in the p53 wild-type tumour cell line HepG2 after $12 \mathrm{~h}$ (Supplementary figure 1B online). As an additional experiment to verify functionally the independence of p53, a specific knockdown of endogenous p53 in HepG2 cells was performed via transfection with p53 siRNA. No significant differences between transfected cells with non-coding siRNAs and p53 siRNAs were detected in the LDH toxicity assay after co-treatment with 5-aza-CR and TRAIL (Supplementary figure 11 online). These investigations strongly indicate a p53-independent mode of action.

Several levels of resistance to TRAIL have been described so far. $^{39}$ Considering the most upstream level in the signal 


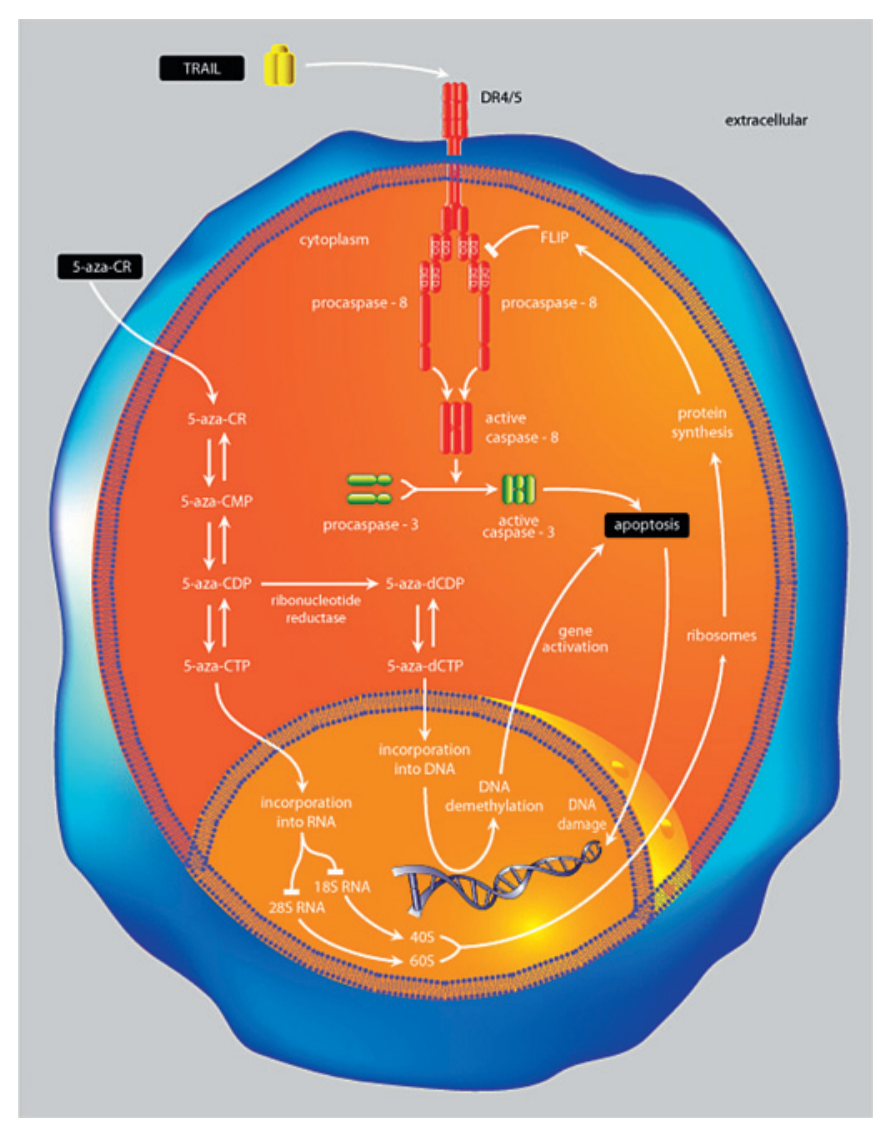

Figure 8 Dual mode of action of 5-azacytidine (5-aza-CR): demethylation of cellular DNA and inhibition of protein biosynthesis in tumour necrosis factor-related apoptosis-inducing ligand (TRAIL)-resistant tumour cells. The constitutive expression of intracellular antiapoptotic factors such as $\mathrm{FLIP}_{\mathrm{L}}$ protects tumour cells such as hepatoma cells against TRAIL-induced apoptosis. Following cell entry of 5 -aza-CR and its conversion to 5-aza-CTP, incorporation into RNA takes place, resulting in a rapid and selective inhibition of $18 \mathrm{~S}$ and $28 \mathrm{~S}$ RNA formation, leading to a block in the synthesis of functional ribosomes. The inhibition of protein synthesis is postulated to induce a quick decrease of regulatory cellular proteins, such as the long form of FLICE inhibitory protein (FLIP $\mathrm{L}_{\mathrm{L}}$, thereby restoring sensitivity to TRAIL in hepatoma cells. Simultaneously, 5 -aza-CR is converted by the ribonucleotide reductase into the corresponding deoxynucleotide 5 -aza-dCTP, this being a prerequisite for incorporation into cellular DNA as a prerequisite for its epigenetic mode of action. This enzymatic step is not required for the related drug 5-aza2 -deoxycytidine (5-aza-dC), which is directly phosphorylated to 5-azadCTP after cell entry, without the ability for incorporation into RNA.

transduction of TRAIL in tumour cells, we excluded an upregulation of the proapoptotic receptors DR4 or DR 5 by 5 -aza-CR as a possible mechanism of sensitisation of TRAIL (Supplementary figure 12 online). Besides HCC, other tumour entities such as prostate or renal cancer have been reported to display a FLIP-mediated resistance to TRAIL. ${ }^{30}{ }^{40} \mathrm{~A}$ study in human renal carcinoma cells ${ }^{30}$ applying $\mathrm{CHX}$ and our own results reinforce the importance of consistency of protein synthesis in tumour cells in order to maintain a TRAIL resistance phenotype. It is important to note that even though CHX and 5 -aza-CR operate in this particular situation with a related mode of action, any therapeutic application of CHX in vivo is definitely excluded, due to the fact that CHX exerts dramatic toxic side effects. In contrast, 5 -aza-CR is approved for clinical application and possesses the additional capacity to modulate the epigenetic pattern of cancer cells as a potent
DNMT inhibitor compound, which suggests that 5-aza-CR might be an ideal combination partner in therapeutic settings that require the inhibition of tumour-protecting proteins to overcome treatment resistance.

In the context of TRAIL, hepatotoxicity has repeatedly been an important issue. ${ }^{32} 33$ Therefore, we applied, in addition to non-malignant colon cell lines, two different toxicity screening approaches with human-derived hepatocytes: PHHs and liver slices from surgically resected human specimens. As an important result and in clear contrast to the tested tumour entities, we could not detect an 5-aza-CR-mediated sensitisation to TRAIL in any of the three toxicity models applying enzyme release, caspase activity and cell survival assays, paving the way for a possible clinical evaluation of our concept. Interestingly, a recently reported phase I dose-escalating study with TRAIL in humans did not show any relevant liver toxicity. ${ }^{41}$ The concentrations in that study were much higher than in our cell culture systems, reaching peak concentrations of up to $279 \mu \mathrm{g} /$ $\mathrm{ml}$. Therefore, liver toxicity seems not to be a major problem of TRAIL itself in humans. However, preliminary data should be kept in mind when designing phase I/II clinical trials involving TRAIL, which suggested that patients with an active hepatitis $C$ infection or a fatty liver disease might be prone to liver-related toxicities. $^{42} 43$

5 -Aza-CR is well known for its epigenetic mode of action due to a strong inhibition of DNMT enzymes. Furthermore, several reports found that 5 -aza-CR induces a $\mathrm{G}_{2} / \mathrm{M}$ cell cycle arrest in different tumour cells. ${ }^{44}{ }^{45}$ In fact, epigenetic alterations are an important hallmark of $\mathrm{HCC}^{3-5}$ for example the gene for suppressor of cytokine signalling (SOCS-1) is known to be methylated in most HCCs and its methylation-induced inactivation has been attributed an important role in the development of HCC. ${ }^{46}$ We previously could show that incubation of HepG2 hepatoblastoma cells for $48 \mathrm{~h}$ with $5 \mu \mathrm{mol} / 15$-aza-dC efficiently demethylates the SOCS-1 gene. ${ }^{47}$ Regarding 5 -aza-CR, we also found a profound demethylation of SOCS-1 in HepG2 cells by applying $5 \mu \mathrm{mol} / 1$ for $48 \mathrm{~h}$ (data not shown), which underlines the capacity of 5-aza-CR for antitumour efficacy at several independent levels in the context of HCC.

In conclusion, the proposed combination of 5 -aza-CR and TRAIL benefits from different modes of action. Whereas 5-azaCR initially blocks protein biosynthesis and thereby restores the sensitivity for TRAIL-induced apoptosis, it subsequently also demethylates cellular DNA, resulting in an activation of silenced regulatory genes. This new antitumour strategy might be a therapeutic option not only in HCC, but also for other tumour entities displaying a resistance to TRAIL and an accumulation of hypermethylated $\mathrm{CpG}$ islands within cellular control genes, for example renal, colon or pancreatic cancer.

Acknowledgements The authors thank Andrea Schenk and Irina Smirnow for excellent technical assistance.

Funding This work was supported in part by grants from the Deutsche Forschungsgemeinschaft SFB 773, from the Ministry for Nutrition and Rural Territories and the Ministry for Science, Research and Arts of Baden-Wuerttemberg, Germany (Kap. 0802, Title 98174). The work of SF was funded by the EU (ApopTrain), and SV was supported by a grant from the Interdisciplinary Center of Clinical Research Tuebingen (IZKF).

\section{Competing interests None.}

Ethics approval The work contains material from human subjects (primary cells and tissue slices). The Ethics Committee at Tübingen, Germany, has approved the usage of these materials.

Contributors MB and UML share senior authorship.

Provenance and peer review Not commissioned; externally peer reviewed. 


\section{REFERENCES}

1. Schulze-Bergkamen $\mathbf{H}$, Weinmann $A$, Moehler $\mathbf{M}$, et al. Novel ways to sensitise gastrointestinal cancer to apoptosis. Gut 2009;58:1010-24.

2. Llovet JM, Ricci S, Mazzaferro V, et al. Sorafenib in advanced hepatocellular carcinoma. N Engl J Med 2008;359:378-90.

3. Calvisi DF, Ladu S, Gorden A, et al. Mechanistic and prognostic significance of aberrant methylation in the molecular pathogenesis of human hepatocellular carcinoma. J Clin Invest 2007:117:2713-22.

4. Tischoff I, Tannapfel A. DNA methylation in hepatocellular carcinoma. World $\mathrm{J}$ Gastroenterol 2008;14:1741-8.

5. Nishida N, Nagasaka T, Nishimura T, et al. Aberrant methylation of multiple tumor suppressor genes in aging liver, chronic hepatitis, and hepatocellular carcinoma. Hepatology 2008:47:908-18.

6. Kornblith AB, Herndon JE, Silverman LR, et al. Impact of azacytidine on the quality of life of patients with myelodysplastic syndrome treated in a randomized phase III trial: a Cancer and Leukemia Group B study. J Clin Oncol 2002;20:2441-52.

7. Kantarjian H, Issa JP, Rosenfeld CS, et al. Decitabine improves patient outcomes in myelodysplastic syndromes: results of a phase III randomized study. Cancer 2006:106:1794-803

8. Stresemann C, Lyko F. Modes of action of the DNA methyltransferase inhibitors azacytidine and decitabine. Int J Cancer 2008;123:8-13.

9. Cihák A, Weiss JW, Pitot HC. Characterization of polyribosomes and maturation of ribosomal RNA in hepatoma cells treated with 5-azacytidine. Cancer Res 1974:34:3003-9.

10. Reuveni Y, Rosenthal LJ. Effect of 5-azacytidine on cytoplasmic ribosomal and messenger ribonucleic acids in BSC-1 cells. Antimicrob Agents Chemother 1979:15:235-9.

11. Cohen MB, Glazer RI. Cytotoxicity and the inhibition of ribosomal RNA processing in human colon carcinoma cells. Mol Pharmacol 1985;27:308-13.

12. Thorburn A, Behbakht K, Ford H. TRAIL receptor-targeted therapeutics: resistance mechanisms and strategies to avoid them. Drug Resist Updat 2008;11:17-24.

13. Ganten TM, Koschny R, Sykora J, et al. Preclinical differentiation between apparently safe and potentially hepatotoxic applications of TRAIL either alone or in combination with chemotherapeutic drugs. Clin Cancer Res 2006;12:2640-6.

14. Armeanu S, Lauer UM, Smirnow I, et al. Adenoviral gene transfer of tumor necrosis factor-related apoptosis-inducing ligand overcomes an impaired response of hepatoma cells but causes severe apoptosis in primary human hepatocytes. Cancer Res 2003:63:2369-72.

15. Ganten TM, Koschny $\mathrm{R}$, Haas TL, et al. Proteasome inhibition sensitizes hepatocellular carcinoma cells, but not human hepatocytes, to TRAIL. Hepatology 2005; 42:588-97.

16. Pathil A, Armeanu S, Venturelli S, et al. HDAC inhibitor treatment of hepatoma cells induces both TRAIL-independent apoptosis and restoration of sensitivity to TRAIL. Hepatology 2006:43:425-34.

17. Mucha SR, Rizzani A, Gerbes AL, et al. JNK inhibition sensitises hepatocellular carcinoma cells but not normal hepatocytes to the TNF-related apoptosis-inducing ligand. Gut 2009:58:688-98.

18. Eggert A, Grotzer MA, Zuzak TJ, et al. Resistance to tumor necrosis factor-related apoptosis-inducing ligand (TRAIL)-induced apoptosis in neuroblastoma cells correlates with a loss of caspase-8 expression. Cancer Res 2001:61:1314-19.

19. Eramo A, Pallini R, Lotti F, et al. Inhibition of DNA methylation sensitizes glioblastoma for tumor necrosis factor-related apoptosis-inducing ligand-mediated destruction. Cancer Res 2005;65:11469-77.

20. Xu J, Zhou JY, Tainsky MA, et al. Evidence that tumor necrosis factor-related apoptosis-inducing ligand induction by 5-aza-2' -deoxycytidine sensitizes human breast cancer cells to adriamycin. Cancer Res 2007:67:1203-11.

21. Weiland T, Weiller M, Kunstle G, et al. Sensitization by 5-azacytidine towards death receptor-induced hepatic apoptosis. J Pharmacol Exp Ther 2009;328:107-15.

22. Thasler WE, Weiss TS, Schillhorn K, et al. Charitable state-controlled foundation human tissue and cell research: ethic and legal aspects in the supply of surgically removed human tissue for research in the academic and commercial sector in Germany. Cell Tissue Bank 2003;4:49-56.

23. Xing JZ, Zhu L, Jackson JA, et al. Dynamic monitoring of cytotoxicity on microelectronic sensors. Chem Res Toxicol 2005;18:154-61.
24. $\mathbf{X u ~ J , ~ L i a o ~ L , ~ O i n ~ J , ~ e t ~ a l . ~ I d e n t i f i c a t i o n ~ o f ~ F l i g h t l e s s - I ~ a s ~ a ~ s u b s t r a t e ~ o f ~ t h e ~}$ cytokine-independent survival kinase CISK. J Biol Chem 2009;284:14377-85.

25. Kuefer R, Hofer MD, Altug V, et al. Sodium butyrate and tributyrin induce in vivo growth inhibition and apoptosis in human prostate cancer. Br J Cancer 2004;90:535-41.

26. Vogler M, Walczak H, Stadel D, et al. Targeting XIAP bypasses Bcl-2-mediated resistance to TRAIL and cooperates with TRAIL to suppress pancreatic cancer growth in vitro and in vivo. Cancer Res 2008;68:7956-65.

27. Okano H, Shiraki $\mathrm{K}$, Inoue $\mathrm{H}$, et al. Cellular FLICE/caspase-8-inhibitory protein as a principal regulator of cell death and survival in human hepatocellular carcinoma. Lab Invest 2003;83:1033-43.

28. Miyamoto Y, Takikawa Y, De Lin S, et al. Apoptotic hepatocellular carcinoma HepG2 cells accelerate blood coagulation. Hepatol Res 2004;29:167-72.

29. Lerche-Langrand C, Toutain HJ. Precision-cut liver slices: characteristics and use for in vitro pharmaco-toxicology. Toxicology 2000:153:221-53.

30. Brooks AD, Sayers TJ. Reduction of the antiapoptotic protein cFLIP enhances the susceptibility of human renal cancer cells to TRAIL apoptosis. Cancer Immunol Immunother 2005;54:499-505.

31. El-Serag HB, Marrero JA, Rudolph L, et al. Diagnosis and treatment of hepatocellular carcinoma. Gastroenterology 2008:134:1752-63.

32. Jo M, Kim TH, Seol DW, et al. Apoptosis induced in normal human hepatocytes by tumor necrosis factor-related apoptosis-inducing ligand. Nat Med 2000:6:564-7.

33. Lawrence D, Shahrokh Z, Marsters S, et al. Differential hepatocyte toxicity of recombinant Apo2L/TRAIL versions. Nat Med 2001;7:383-5.

34. El-Serag HB, Rudolph KL. Hepatocellular carcinoma: epidemiology and molecular carcinogenesis. Gastroenterology 2007:132:2557-76.

35. Lee TK, Lau TC, Ng IO. Doxorubicin-induced apoptosis and chemosensitivity in hepatoma cell lines. Cancer Chemother Pharmacol 2002:49:78-86.

36. Kusumoto M, Ogawa T, Mizumoto K, et al. Adenovirus-mediated p53 gene transduction inhibits telomerase activity independent of its effects on cell cycle arres and apoptosis in human pancreatic cancer cells. Clin Cancer Res 1999:5:2140-7.

37. O'Connor PM, Jackman J, Bae I, et al. Characterization of the p53 tumor suppressor pathway in cell lines of the National Cancer Institute anticancer drug screen and correlations with the growth-inhibitory potency of 123 anticancer agents. Cancer Res 1997; 57:4285-300

38. Soussi T. The p53 tumor suppressor gene: from molecular biology to clinical investigation. Ann N Y Acad Sci 2000:910:121-37.

39. Zhang L, Fang B. Mechanisms of resistance to TRAlL-induced apoptosis in cancer Cancer Gene Ther 2005:12:228-37.

40. Zhang $\mathbf{X}$, Jin TG, Yang $\mathrm{H}$, et al. Persistent c-FLIP(L) expression is necessary and sufficient to maintain resistance to tumor necrosis factor-related apoptosis-inducing ligand-mediated apoptosis in prostate cancer. Cancer Res 2004;64:7086-91.

41. Herbst RS, Eckhardt SG, Kurzrock R, et al. Phase I dose-escalation study of recombinant human Apo2L/TRAIL, a dual proapoptotic receptor agonist, in patients with advanced cancer. J Clin Oncol 2010:28:2839-46.

42. Volkmann X, Fischer U, Bahr MJ, et al. Increased hepatotoxicity of tumor necrosis factor-related apoptosis-inducing ligand in diseased human liver. Hepatology 2007:46:1498-508.

43. Lan L, Gorke S, Rau SJ, et al. Hepatitis C Virus infection sensitizes human hepatocytes to TRAIL-induced apoptosis in a caspase 9-dependent manner. $\mathrm{J}$ Immunol 2008;181:4926-35

44. Schneider-Stock R, Diab-Assef M, Rohrbeck A, et al. 5-aza-cytidine is a potent inhibitor of dna methyltransferase 3 a and induces apoptosis in HCT-116 colon cancer cells via Gadd45- and p53-dependent mechanisms. J Pharmacol Exp Ther 2005:312:525-36.

45. Alexander VM, Roy M, Steffens KA, et al. Azacytidine induces cell cycle arrest and suppression of neuroendocrine markers in carcinoids. Int J Clin Exp Med 2010:3:95-102

46. Yoshikawa H, Matsubara K, Qian GS, et al. SOCS-1, a negative regulator of the JAK/STAT pathway, is silenced by methylation in human hepatocellular carcinoma and shows growth-suppression activity. Nat Genet 2001:28:29-35.

47. Venturelli S, Armeanu S, Pathil A, et al. Epigenetic combination therapy as a tumor-selective treatment approach for hepatocellular carcinoma. Cancer 2007:109:2132-41 


\section{GUT}

Dual antitumour effect of 5-azacytidine by inducing a breakdown of resistance-mediating factors and epigenetic modulation

Sascha Venturelli, Alexander Berger, Timo Weiland, Martina Zimmermann, Sabine Häcker, Christoph Peter, Sebastian Wesselborg, Alfred Königsrainer, Thomas S Weiss, Michael Gregor, Simone Fulda, Ulrich M Lauer and Michael Bitzer

Gut 2011 60: 156-165 originally published online November 23, 2010 doi: 10.1136/gut.2010.208041

Updated information and services can be found at:

http://gut.bmj.com/content/60/2/156

These include:

Supplementary Supplementary material can be found at:

Material http://gut.bmj.com/content/suppl/2011/01/24/gut.2010.208041.DC1

References This article cites 47 articles, 20 of which you can access for free at: http://gut.bmj.com/content/60/2/156\#BIBL

Email alerting Receive free email alerts when new articles cite this article. Sign up in the service box at the top right corner of the online article.

Topic Articles on similar topics can be found in the following collections Collections

\section{Notes}

To request permissions go to:

http://group.bmj.com/group/rights-licensing/permissions

To order reprints go to:

http://journals.bmj.com/cgi/reprintform

To subscribe to BMJ go to:

http://group.bmj.com/subscribe/ 